
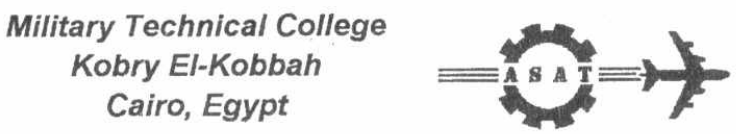

$10^{\text {th }}$ International Conference

On Aerospace Sciences\&

Aviation Technology

\title{
EXPERIMENTAL AND NUMERICAL INVESTIGATION OF THE INFLUENCE OF FREE-STREAM TURBULENCE ON TURBULENT BOUNDARY LAYER DRAG REDUCTION OVER PLATES WITH STREAM-WISE MICRO-GROOVES
}

\begin{abstract}
Reda I. Afify ${ }^{*}$
M. Fayek Abd-Rabbo

ABSTRACT

Experimental and numerical studies are performed to investigate the effect of freestream turbulence on turbulent boundary layer drag reduction over plates with stream-wise micro-grooves. The data includes mean velocity, turbulence intensities, momentum thickness, and skin friction. Riblet or grooved plates of various riblet aspect ratios $(\mathrm{h} / \mathrm{s})$ have been machined with symmetrical, sharp, stream-wise triangular-shaped grooves having a peak-to-valley height (h) and peak-to-peak width (s). Three test plates, one smooth and two with triangular profile grooves (riblets) of $\mathrm{h} / \mathrm{s}=0.7$, and 1.3 aspect ratio with fixed riblet spacing $(\mathrm{s}=0.6 \mathrm{~mm})$, have been used in this comparative study. Three screens of different sizes inserted upstream the test plates (with and without grooves) were used to study the effect of the free-stream turbulence. The turbulence intensities level varied from $1.3 \%$ to $3.2 \%$ by the screens. The Reynolds number based on the free-stream velocity and the streamwise length, ranged from $1.4 \times 10^{6}$ to $4.3 \times 10^{6}$ covering a range of riblet spacing in wall units $\left(\mathrm{s}^{+}\right), \mathrm{s}^{+}=\mathrm{sU}_{\tau} / v$, of 13.7 to 36.4 . The measurements were made in a suction type, low-speed open-return wind tunnel using a Dantec 56C01 constant temperature anemometer (CTA) with a Dantec 55P04 hot single-wire probe. The numerical investigation has been formulated using a finite difference method and $k-\varepsilon$ turbulence model. The results show that the drag increases with increasing the freestream turbulence. The data show that the drag reduction occurred whenever riblet spacing in wall units in range of $0<\mathrm{s}^{+}<25$. For grooved plates without screens, a maximum drag reduction of $9 \%$ occurred at $\mathrm{s}^{+}=13.7$. The maximum drag reduction reached $6.3 \%$ in the case of grooved plate with $\mathrm{h} / \mathrm{s}=1.3$ with turbulence promoter compared with the smooth surface without turbulence promoters. Also, the results suggest increased the effectiveness of the riblets with turbulence promoters compared with the smooth surface with turbulence promoters.
\end{abstract}

\section{KEY WORDS}

Free-stream turbulence, Drag reduction, Turbulence intensities, Stream-wise microgrooves.

\footnotetext{
* Associate Prof., Mech. Eng. Dept., Shoubra Faculty of Engineering, Zagazig University.

** Professor, Mech. Power Eng. Dept., Faculty of Engineering, Cairo University.

*** Professor, Mech. Eng. Dept., Shoubra Faculty of Engineering, Zagazig University.

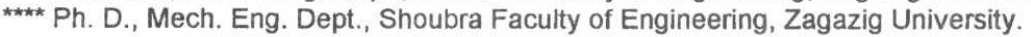


bodies, and long distance pipelines. Among the various drag reduction techniques which have been tested experimentally to date, the technique of using longitudinal riblet surfaces aligned in the stream-wise direction seems to be promising and is also relatively simple to implement.

Riblets, which are stream-wise grooves of very small dimensions, are currently being investigated as a promising method for the reduction of turbulent skin friction drag of airfoils, nacelles, and aircraft fuselages. One of the better drag-reducing geometries found, and employed here, are symmetric, sharply peaked, V-groove riblets. The grooves (micro surface) geometries are aligned with the flow and defined by peak-tovalley height, $h$, peak-to-peak spacing, $s$. These riblets provide 5 to 7 percent drag reduction when the riblet height in wall units, $\mathrm{h}^{+}=\mathrm{hU}_{\tau} / \mathrm{v}$, varied between 11 and 15 [1-3], where $U_{\tau}$ and $v$ denote the wall-shear velocity and kinematic viscosity, respectively. The concept of the viscous drag reduction technique using riblet surfaces has been examined experimentally and numerically by many investigators [1-20].

The effect of free-stream turbulence on turbulent momentum and heat transfer in boundary layers has relevance to turbomachines fluid mechanics, in that the flow at a downstream stage essentially suffers from turbulence generated by the upstream stages, as well as periodic unsteadiness induced by blades. The influence of freestream turbulence on turbulent boundary layers can be though of as due to the interaction of different turbulence fields with different length and velocity scale distributions. The experiments by Simonich and Bradshaw [21] using (910-mm $\times$ $910-\mathrm{mm}$ ) wind tunnel suggested that the fractional changes of either skin friction coefficient $\left(\mathrm{C}_{\mathrm{f}}\right)$ or Stanton number $(\mathrm{St})$ are linear with rms longitudinal turbulence intensity. They ignored any effects of turbulence length scale. Hancock and Bradshaw [22] performed a series of experiments on the same tunnel (910-mm $\times$ $910-\mathrm{mm}$ ) to study the effect of grid turbulence on skin friction coefficient with a wide range of turbulence length scales. They put a non-linear correlation for the fractional change in skin friction coefficient with both velocity and length scales. For flat plate studies, numerous correlations between the free-stream turbulence intensity and length scale have been developed, e.g., Roach and Brierley [23] and Westin et al. [24]. By restricting consideration to the Reynolds analogy factor, $\mathrm{St}_{/}\left(\mathrm{C}_{\mathrm{f}} / 2\right)$, Blair [25] found a good agreement between Stanton number measurements in grid-turbulence and that obtained by Hancock and Bradshaw. MacMullin et al. [26], Baskaran et al. [27], Abdellatif [28] have found that Stanton number increases as well as the increase of skin friction coefficient but with different factor depending on the turbulence level of free-stream turbulence.

To the author's best knowledge, there have not been any investigations study the effect of free-stream turbulence on turbulent boundary layer drag reduction over plates with stream-wise micro-grooves in the open literature. Therefore, the objective of the present study is to investigate, experimentally and numerically, the effect of free-stream turbulence on turbulent boundary layer drag reduction over plates with stream-wise triangular-shaped micro-grooves. It is also of interest, to see whether the above trend of the drag reduction with micro-grooved plates is still valid. 


\section{APPARATUS, MEASURING INSTRUMENTS AND PROCEDURES}

The experiments were conducted in a suction type, low-speed open-return wind tunnel designed to give a stable uniform air-flow with low turbulence level. For clean tunnel (without grid), the working section free-stream turbulence intensity at the centerline of the tunnel in the potential core is about $1.3 \%$. This tunnel has a 2700 $\mathrm{mm}$ long test section with a cross section $280 \mathrm{~mm}$ high and $300 \mathrm{~mm}$ wide. Figure 1 shows the schematic diagram of the working section of the wind tunnel. The tests were carried out at different free-stream velocities. The Reynolds number, Re, based on the free-stream velocity $\left(\mathrm{U}_{\infty}\right)$ and the stream-wise length from beginning of the test section of the wind tunnel, ranged from $1.4 \times 10^{6}$ to $4.3 \times 10^{6}$. The set-up is designed to provide accurate air-flow.

Interchangeable plates $200 \mathrm{~mm}$ wide and $500 \mathrm{~mm}$ long were machine cut from aluminum and available for the experiments. These were placed on the tunnel floor $2100 \mathrm{~mm}$ from the beginning of the working section. The tested surface was placed in the same plane of the horizontal lower wall of the test section in order to avoid the bluntness effect over the plate. The riblets, which are stream-wise grooves of very small dimensions (micro-grooves), are aligned with the flow. Riblet plates of various riblet aspect ratios $(\mathrm{h} / \mathrm{s})$ have been machined with symmetrical, sharp, triangularshaped grooves having a peak-to-valley height (h) and peak-to-peak width (s), as shown in Fig. 2. Three test plates, one smooth and two with triangular profile riblets of $\mathrm{h} / \mathrm{s}=0.7$, and 1.3 aspect ratio with fixed riblet spacing $(\mathrm{s}=0.6 \mathrm{~mm})$, have been used in this comparative study. The test plates have been machined by Arab Sakr Factory for Developed Industries. Three screens of different sizes $(300-\mathrm{mm} \times 300-$ $\mathrm{mm}$ cross section) inserted upstream the test plates (with and without grooves) were used to study the effect of the free-stream turbulence, as shown in Fig. 3. The leading edge is adjusted to be $1100 \mathrm{~mm}$ downstream the turbulence-generating screen location. Screen (1) consists of a horizontal bars equally spaced at $7-\mathrm{mm}$, each one has a diameter of 2-mm. The screen (1) produce free-stream turbulence intensity of $2.5 \%$. Two biplane turbulence-generating grids, screen (2) and screen (3), with square bars were used. The screen includes a grid of square mesh $47-\mathrm{mm}$ [screen (2)] and 37-mm [screen (3)]. The bars which constitute the mesh has a diameter of $7-\mathrm{mm}$. The free-stream turbulence intensities were about $2.8 \%$ and $3.2 \%$ for screen (2) and screen (3), respectively.

The mean and turbulent fluctuating velocities parallel to the mean flow direction were measured with a Dantec 56C01 constant temperature anemometer (CTA) with a Dantec 55P04 single-wire probe of $5 \mu \mathrm{m}$ diameter platinum-plated tungsten wire. The hot-wire probe has been mounted on a two-dimensional traverse mechanism of Dantec $56 \mathrm{H} 00$ model. The system is digitally controlled and easily interfaced to the computer and it allows the creation of a completely automatic flow measuring system.

The drag reduction performance of riblets has typically been measured using both drag balances and velocity profiles. The drag balances introduce errors due to misalignment. Also, in the few experiments where the riblets were large, the velocity gradient at the wall was used to obtain the local skin friction. In the present work, the riblets are physically too small to measure the wall velocity gradient, and boundary 
layer velocity profiles are integrated to obtain the momentum thickness. As Walsh et al. [3] and Gallagher and Thomas [4], the changes in the momentum thickness are then related to the skin friction. The Von Karman momentum integral equation in terms of the coefficient of friction, for a 2-dimensional incompressible boundary layer, may be written as:

$$
\frac{\mathrm{d} \theta}{\mathrm{d} x}=\frac{\mathrm{C}_{\mathrm{f}}}{2}-\left(\frac{\delta^{*}}{\theta}+2\right) \frac{\theta}{\mathrm{U}_{\mathrm{o}}} \cdot \frac{\mathrm{dU_{ \textrm {o } }}}{\mathrm{dx}}
$$

where

$$
\theta=\int_{0}^{\delta} \frac{U}{U_{0}}\left(1-\frac{U}{U_{0}}\right) d y \text { and } \delta^{*}=\int_{0}^{\delta}\left(1-\frac{U}{U_{0}}\right) d y
$$

The parameters $x, U_{0}, \theta, \delta^{*}$, and $C_{f}$ are the stream-wise coordinate, free-stream-wise velocity, momentum thickness, displacement thickness and skin friction coefficient.

For a zero pressure gradient equation (1) reduces to

$$
C_{f}=2 \frac{d \theta}{d x}
$$

This permits evaluation of $\mathrm{C}_{\mathrm{f}}$ by graphical differentiation of the momentum thickness $\theta(x)$. In the present investigation, to obtain the momentum thickness the boundary layer velocity profiles are integrated at five sections in stream-wise direction. The distance between each two successive section is $100 \mathrm{~mm}$. The first section is at 25 $\mathrm{mm}$ from beginning of the test plate. The momentum thickness $\theta$ is deduced by integrating the mean velocity profiles using the modified Simpson's rule method as suggested by Coles and Hirst [29]. The drag or the skin friction coefficient is obtained from the change in the momentum thickness to determine the drag performance by riblets.

\section{MATHEMATICAL FORMULATION}

\section{Governing Equations}

The flow is assumed to be two-dimensional steady for an incompressible Newtonian fluid over the tested plates. The buoyancy effects are assumed negligible. The timeaveraged conservation equations for mass and momentum for turbulent fluid flow may be expressed in the following compact tensor form:

$$
\frac{\partial u_{i}}{\partial x_{j}}
$$




$$
U_{j} \frac{\partial U_{i}}{\partial x_{j}}=-\frac{1}{\rho} \frac{\partial p}{\partial x_{i}}+\frac{\partial}{\partial x_{j}}\left(v \frac{\partial U_{i}}{\partial x_{j}}-\overline{u_{i}^{\prime} u_{j}^{\prime}}\right)
$$

where $U_{i}$ and $u_{i}^{\prime}$ are the time-averaged and fluctuating velocity components in the coordinate directions $x_{i}, \rho$ is the fluid density, $p$ is the local pressure, and the terms $-\overline{u_{i}^{\prime} u_{j}^{\prime}}$ are the Reynolds stresses.

The Reynolds stresses $-\overline{u_{i}^{\prime} u_{j}^{\prime}}$ appearing in the time-averaged Navier-Stokes equations represent the transfer of momentum by turbulent motion per unit mass. Exact equations for the Reynolds stresses can be derived, but requires a turbulent model to close the mathematical problem. Based on the turbulence model postulations summarized by Sheikholeslami [30] a second order closure turbulence model for turbulent kinetic energy $(k)$ and dissipation rate $(\varepsilon)$ equations can be modelled as

$$
\begin{aligned}
& \frac{D k}{D t}=\frac{\partial}{\partial x_{m}}\left[C_{k} \frac{k^{2}}{\varepsilon} \frac{\partial k}{\partial x_{m}}+v \frac{\partial k}{\partial x_{m}}\right]-\overline{u_{i}^{\prime} u_{j}^{\prime}} \frac{\partial U_{i}}{\partial x_{m}}-\varepsilon \\
& \frac{D \varepsilon}{D t}=\frac{\partial}{\partial x_{m}}\left[C_{\varepsilon} \frac{k^{2}}{\varepsilon} \frac{\partial \varepsilon}{\partial x_{m}}+v \frac{\partial \varepsilon}{\partial x_{m}}\right]-C_{\varepsilon 1} \overline{u_{i}^{\prime} u_{j}^{\prime}} \frac{\partial U_{i}}{\partial x_{m}}-C_{\varepsilon 2} \frac{\varepsilon^{2}}{k}
\end{aligned}
$$

where $\mathrm{C}_{\mathrm{k}}, \mathrm{C}_{\varepsilon}, \mathrm{C}_{\varepsilon 1}$, and $\mathrm{C}_{\varepsilon 2}$ are model constants which are determined from experiments. These constants are: $C_{k}=C_{\varepsilon}=0.09, C_{\varepsilon 1}=1.45$, and $C_{\varepsilon 2}=1.9$ [31].

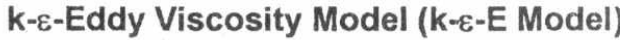

Boussinesq noted that the viscous stress is proportional to velocity gradients in laminar flow and proposed that the Reynolds stresses are also proportional to velocity gradients with an eddy viscosity $\left(v_{t}\right)$ as the proportional constant. The $k-\varepsilon$ model relates the Reynolds stresses to the gradients of the mean velocities via exchange coefficients in the following manner:

$$
-\overline{u_{i}^{\prime} u_{j}^{\prime}}=v_{t}\left(\frac{\partial U_{i}}{\partial x_{j}}+\frac{\partial U_{j}}{\partial x_{i}}\right)-\frac{2}{3} \delta_{i j} k
$$

where $v_{\mathrm{t}}$ is the turbulent viscosity, and $\delta_{\mathrm{ij}}=0$ if $\mathrm{i} \neq \mathrm{j}$ and $\delta_{\mathrm{ij}}=1$ if $\mathrm{i}=\mathrm{j}$.

Based on dimensional analysis of $\mathrm{k}$ and $\varepsilon, v_{\mathrm{t}}$ is modeled as Launder and Spalding, [32]

$$
v_{\mathrm{t}}=\mathrm{C}_{\mu} \mathrm{k}^{2} / \varepsilon
$$


$\mathrm{k}$ and $\varepsilon$ are governed by equations (6) and (7), respectively. $\mathrm{C}_{\mu}=0.09$ is a constant determined from experiments.

\section{Numerical Method and Solution Procedure}

By using the control-volume based finite difference method of Patankar [33], governing equations were integrated over a finite number of control volumes covering the entire solution domain, which each control volume containing a grid point. These equations were solved together using the solution procedure described by Patanker. The sequence of numerical operation based on Patankar's SIMPLER (Semi-Implicit Method for Pressure Linked Equation, Revised) algorithm. An estimate of the velocity field at the first iteration was obtained by solving the momentum equations with presumed values of the pressure distribution. Moreover, there is no guarantee that the resultant velocity field will satisfy the continuity equation; therefore, after each calculation over the solution domain, adjustments were made to the pressure and velocity fields to satisfy continuity. The procedure is repeated until convergence is obtained. The results are considered to be numerically converged in the present solution procedure when the maxima of the mass flux and momentum flux residuals summed at all nodes are less than 0.6 percent of the inlet flux.

\section{Boundary Conditions and Grid Layout}

On the wall the non slip conditions applied was $U=V=0$, while at the upper boundary $(y=\delta)$ the normal gradient of the velocity was zero $(\partial U / \partial y=0)$. The value of inlet and outlet turbulent kinetic energy is obtained from the velocity profile. The inlet and outlet profiles of the dissipation rate were determined from its model

$$
\varepsilon=C_{\mu} \cdot k^{3 / 2} / I
$$

where $/$ is the length scale that characterizes the energy containing eddies

All velocity components were presumed zero along the wall. The wall function approach assumes that at a point with wall distance $y_{p}$ just outside the viscous sublayer, the velocity component parallel to the wall and the turbulence is in local equilibrium so that the production is equal to dissipation. The wall functions listed in Habib et al. [31] corresponding to the dependent variables were taken as

$$
\tau_{w}=\mu \frac{U_{p}}{y_{p}} \frac{y_{p}^{+}}{U_{p}^{+}}
$$

where

$$
\mathrm{U}_{\mathrm{p}}^{+}=\frac{1}{\mathrm{~K}} \ln \mathrm{E} \cdot \mathrm{y}_{\mathrm{p}}^{+} \quad \text { and } \mathrm{y}_{\mathrm{p}}^{+}=\mathrm{C}_{\mu}^{1 / 4} \mathrm{k}_{\mathrm{p}}^{2} \cdot \mathrm{y}_{\mathrm{p}} / v
$$


where $\kappa=0.41$ is known as Von Karman constant. The subscript $p$ refers to the node nearest the wall. In the present work, wall parameter $E$ in the logarithmic law of the wall in equation (12) was modified as:

$$
E=e^{k(5.5-F)}
$$

where $\mathrm{F}$ is the constant shift, $\mathrm{F}=-\Delta \mathrm{U} / \mathrm{U}_{\tau}$. The parameter $\Delta \mathrm{U} / \mathrm{U}_{\tau}$ is determined from the experimental data, $\Delta \mathrm{U} / \mathrm{U}_{\mathrm{r}}=0$ for smooth plate without turbulence promoters.

The value of the turbulent kinetic energy near the wall, $k_{p}$, is calculated from the transport equation for $k$ with its flux to the solid wall set to zero. The corresponding value of $\varepsilon_{\mathrm{p}}$ was calculated from equation (10) with $I=\mathrm{C}_{\mu}{ }^{1 / 4} \kappa \mathrm{y}_{\mathrm{p}}$.

The computations to be reported in the following sections were performed on a $90 \times 33$ grid. Additional runs for the coarser $(80 \times 29)$ and finer $(100 \times 37)$ meshes were under-taken for a check of grid independence. The distance from the near-wall node to the nearest wall was kept constant for the three runs. A comparison of the results showed that the maximum changes of 0.8 percent in the axial velocity profiles between $90 \times 33$ and $100 \times 37$ grid sizes were smaller than 3.2 percent found between $90 \times 33$ and $80 \times 29$ mesh sizes. Consequently, the accuracy of the solutions on $90 \times 33$ grid size is deemed satisfactory. More grid nodes are located in the vicinity of the wall region where the velocity gradients are higher. The staggered grid system is adopted in the present investigation.

\section{RESULTS AND DISCUSSION}

All the data for grooved plates have been plotted in terms of groove spacing in wall variables $\left(\mathrm{s}^{+}\right)$for different groove aspect ratio $(\mathrm{h} / \mathrm{s})$ as follows:

$$
\mathrm{s}^{+}=\left(\mathrm{sU}_{\mathrm{o}} / \mathrm{v}\right) \sqrt{\frac{\mathrm{c}_{\mathrm{f}}}{2}}
$$

$\mathrm{h}$ is the riblet height, $\mathrm{s}$ the riblet spacing, $\mathrm{U}_{\infty}$ the free-stream velocity, $v$ the kinematic viscosity, and $\mathrm{C}_{\mathrm{f}}$ the skin friction coefficient.

The present measurements are taken at five sections (stations) in stream-wise direction. The distance between each two successive section is $100 \mathrm{~mm}$. The first section is at $25 \mathrm{~mm}$ from beginning of the test plate.

\section{Smooth Plate Without Grooves (Riblets)}

The effect of free-stream turbulence for smooth plate without grooves (riblets) on mean velocity, turbulence intensity and log law of mean velocity profiles are presented. The experimental and numerical profiles are drawn at $425 \mathrm{~mm}$ from the beginning the test plate. 
The non-dimensional mean velocities $\mathrm{U} / \mathrm{U}_{\infty}$ are plotted against the non-dimensional normal distance from the boundary wall $y / \delta$ using a linear scale, where $\delta$ is the local boundary layer thickness. It was observed that in all cases, where screen (turbulence promoter) is inserted, there is a little reduction in mean velocity values below the corresponding values in the case of no screen, this reduction gradually decreases with $y / \delta$, as shown in Fig. 4. The average percentage of this reduction reached the value of $6.4 \%$ in the case of the screen type (3) with free-stream turbulence intensity (Tu) of $3.2 \%$. The values of mean velocity for smooth plate with $\mathrm{Tu}=3.2 \%$ appear lower than that for smooth plate with $\mathrm{Tu}=2.5 \%$ for screen (1). The bars, constituting the grid, act as a turbulence promoter which increase the possibility of vortices forming in the stream-wise and span-wise directions, which interact with the flow and result in a higher transport of momentum from the resisting wall to the fluid layers producing deceleration action near the wall.

The root mean square ( $\mathrm{rms}$ ) values of the velocity fluctuation normalized by the freestream mean velocity, $U_{\infty}$, and are plotted against $y / \delta$. The profiles for smooth plate with and without turbulence promoters are presented as shown in Fig. 5 . The values of $\mathrm{u}_{\mathrm{rms}} \mathrm{U}_{\infty}$ for smooth plate with turbulence screens were higher than that of without screens case. The free-stream turbulence was observed to reach the values of $2.5 \%$ for the screen type (1), $2.8 \%$ for the screen type (2), not seen in the figure, and $3.2 \%$ for the screen type (3).

The semi-logarithmic velocity profiles over the flat plate with and without screens for free-stream turbulence intensity (Tu) of $2.5 \%$ and $3.2 \%$ are plotted with the nondimensionalized mean velocity by the shear velocity $\left(u^{+}=U / U_{\tau}\right)$, against $y^{+}=y U_{\tau} / v$, $U_{\tau}$ is the shear velocity and $v$ is the kinematic viscosity. The shear velocities are determined by:

$$
U_{\tau}=\sqrt{\frac{\tau_{w}}{\rho}}=U_{0} \sqrt{\frac{C_{f}}{2}}
$$

The present results for flat plate without screen were compared with the universal law of the wall for the flat plate. The values predicted by the universal law of the wall give a reasonable comparison with the present data. The satisfactory agreement in the above comparison has confirmed that the experimental and numerical procedure employed are adequate and the results obtained are reliabie. The universal law of the wall flat plate is given by [34]

$$
\mathrm{u}^{+}=\frac{1}{0.41} \ln \mathrm{y}^{+}+5.5
$$

The discrepancy between the present results and values predicted by the universal law of the wall is typically within $5 \%$.

The effect of screens inserted upstream the test section on the velocity profile appears as a downward shift in the log law region as shown in Fig. 6 . The downward shift is increased with increasing the free-stream turbulence or decreasing the grid size as observed in the figure. The maximum downward shift was observed in the case of the screen type (3) with Tu $=3.2$ to be about $6.7 \%$. 


\section{Grooved Plates}

\section{Mean velocity}

The experimental and numerical profiles of mean velocity over grooved plate $(\mathrm{h} / \mathrm{s}=$ 1.3) with and without turbulence promoters compared with smooth plate without turbulence promoters are plotted in Fig. 7. The experimental and prediction data are plotted at $425 \mathrm{~mm}$ from the beginning of the test plate. The figure shows the mean velocity profiles are affected by grooved surface with and without turbulence promoter. The data show an increase in mean velocity near-wall for grooved plate with $\mathrm{s}^{+}=13.7, \mathrm{~s}^{+}=\mathrm{sU}_{\tau} / v$, compared with smooth plate data without turbulence promoter, as shown in Fig. 8. The experimental and numerical data of $U / \mathrm{U}_{\infty}$ for grooved plate with $\mathrm{s}^{+}=23.4$ appear to be approximately the same as the smooth plate. While the values of $\mathrm{U} / \mathrm{U}_{\infty}$ near-wall for grooved plate with $\mathrm{s}^{+}=36.4$ are lower than that for smooth surface without turbulence promoter.

In summary, the experimental data and prediction data indicate that the changes in the mean velocity due to the grooves seem to be limited to the immediate wall region $y / \delta<0.15$. It will be shown that this apparently small difference in the profiles has a significant effect on the resultant momentum thickness and drag.

\section{Turbulence intensity}

The experimental and numerical profiles of turbulence intensity $\left(\mathrm{U}_{\mathrm{rms}} / \mathrm{U}_{\infty}\right)$ over grooved plate $(h / s=1.3)$ with and without turbulence promoters compared with smooth plate without turbulence promoters are plotted in Fig. 9. Also, the variation of the turbulence intensity near-wall is plotted in Fig. 10. As shown in the figures, the turbulence intensity is reduced by grooved surface for $\mathrm{s}^{+}=13.7$ compared with the smooth surface without turbulence promoters. While the turbulence intensity is increased over the grooved surface with $\mathrm{s}^{+}=36.4$. The turbulence intensity distributions clearly indicate the significant influence of grooved plate with turbulence promoter. It is clear from these figures that the present numerical technique and turbulence model is in good agreement with present experimental data.

In summary, the experimental data and prediction data indicate that the maximum turbulence intensity occurred at about the same y location as that for a smooth plate. The shift in turbulence intensity data is believed to be an indication that more than one mechanism is responsible for drag reduction by grooved plates. The decreases in the turbulence intensity over the grooved plate reflect the effectiveness of the riblets in reducing the momentum transport to the surface. The data indicates that the turbulence intensity over the grooved plate is a function of the spacing in wall units $\left(s^{+}\right)$. 


\section{Momentum thickness}

In order to obtain the coefficient of friction $\mathrm{C}_{\mathrm{f}}$ using the method of the momentum integral equation, mean velocity traverses are carried out. The momentum thickness $\theta$ is deduced by integrating the mean velocity profiles using the modified Simpson's rule method as suggested by Coles and Hirst [29].

From the velocity profiles the momentum thickness was calculated. The variation with $x-x_{\text {ref }}$ (Note: $x_{\text {ref }}$ refers to stream-wise distance from the leading edge of the working section to the leading edge of the test plate) of momentum thickness $\theta$ is shown in Fig. 11 for smooth without turbulence promoters and riblet surfaces with and without screens.

The momentum thickness values for riblets with $\mathrm{h} / \mathrm{s}=1.3$ are plotted in Fig. 11 at $s^{+}=13.7,23.4$ and 36.4 . Note that at each stream-wise position $\left(x-x_{\text {ref }}\right)$ the momentum thickness above the riblet plate at $s^{+}=13.7$ is both smaller and is increasing more slowly linearly than the comparable momentum thickness above the smooth plate without turbulence promoters. At the dimensionless riblet spacing $\mathrm{s}^{+}=$ 23.4, the momentum thickness values are seemed approximately identical for both the riblet plate with and without screen and the smooth plate without screens. The figure indicates also that the momentum thickness for the riblet surface at $s^{+}=36.4$ is higher and is increasing rapidly with $x-x_{\text {ref }}$ than that for smooth surface without turbulence promoters. It is evident from Fig. 11 that the slope of the momentum thickness over above both smooth plate without screen and grooved plate with and without screen is constant and this indicates that the skin friction is constant on the wall of test plate. The slope of the momentum thickness over the grooved surface with turbulence promoter is higher compared with the grooved surface without turbulence promoter.

Also, the results of all parameters indicate excellent agreement between the present prediction and measurements.

\section{Log law of mean velocity profiles}

The mean velocity profiles, normalized by local wall shear velocity, above both smooth plate without screen and grooved plate with and without screen are shown in Fig. 12. The effect of grooves (riblets) and screens inserted upstream the test section on the velocity profile appears as a shift in the log law region or a thickening of the sublayer. Figure 12 display the cumulative law of the wall velocity profiles for both smooth surface without turbulence promoters and riblet surface $(h / s=1.3)$ with and without screens. The slope of the log law over the riblet surface with and without screens remains the same as that of the smooth surface without free-stream turbulence promoters; however, the intercept of the law is upward shift by riblets with $\mathrm{s}^{+}<20-30$, and is the downward shift by riblets with $\mathrm{s}^{+}>20-30$. The upward shift is associated with decreased values of friction velocity or skin friction, and the downward shift indicates skin friction increases. The velocity distributions clearly indicate the significant influence of grooved plate with turbulence promoter. 
This upward shift in the velocity profiles has been observed in other riblets studies without free-stream turbulence (screen) $[5,6,13]$. The upward shift can be considered as an adjustment of the balance between the turbulence energy production and the viscous dissipation, which is reflected by a change of viscous sublayer thickness or the smallest size of turbulent eddies in the boundary layer [5]. Therefore the turbulence energy production is less with an upward shift of the loglaw curve, resulting in the reduction of turbulent drag. The downward shift in the log region has been previously seen in sand grain roughness studies [35, 36].

The results of law of wall velocity profiles indicate good agreement between the present prediction and measurements. The maximum discrepancies observed is $8 \%$ near the wall due to effects of heat conduction to the wall. Also, the discrepancies observed in the results are due to the inaccuracy of the measurements and/or the effect of three-dimensionality.

The present data indicate that the drag reduction performance of V-groove riblets scales or correlates with groove riblet height (h) and spacing (s) in law-of-the-wall variables.

The present work evaluates the riblet drag reduction performance in terms of the velocity profile expression using Coles [34] model given here,

$$
\frac{\mathrm{U}}{\mathrm{U}_{\tau}}=\frac{1}{\mathrm{~K}} \ln \frac{\mathrm{U}_{\tau} \mathrm{y}}{\mathrm{v}}+5.5+\frac{\pi}{\mathrm{K}} \mathrm{w}\left(\frac{\mathrm{y}}{\delta}\right)-\mathrm{F}
$$

where $w(y / \delta)$ is the wake function and it is approximated by:

$$
w\left(\frac{y}{\delta}\right)=2 \sin ^{2}\left(\frac{\Pi}{2} \frac{y}{\delta}\right)
$$

The quantity $\pi$, called Coles wake parameter, and it is independent of $y$. The value of Von Karman constant $\mathrm{k}$ is $0.41 . \mathrm{F}$ is the constant shift of the linear region [when plotted $U / U_{\tau}$ vs. In $\left.y U_{\tau} / v\right], F=-\Delta U / U_{\tau}$. The parameter $\Delta U / U_{\tau}$ is determined from present experimental data. The parameter $\Delta U / U_{\tau}$ is upward shift in the velocity profiles in wall coordinates when drag reduction occurs and downward shift in the velocity profiles in wall coordinates when drag increase occurs. The experimental data of $\mathrm{F}$ are plotted in Figs 13 and 14 versus the Reynolds number for the smooth plates without grooves and $\mathrm{s}^{+}$for the grooved plates, respectively. The results shown in this figure indicate that $F$ is negative when drag reduction occurs and positive when drag increase occurs. One would expect $F$ to reach a minimum and the drag reduction to reach a maximum, and then both $\mathrm{F}$ and the drag reduction percentage to approach zero as the roughness spacing in wall units $\left(\mathrm{s}^{+}\right)$approaches zero. The positive values of the riblets parameter $F$ for the grooved plates with turbulence promoters are higher in magnitude in comparison to the grooved plates without turbulence promoters. While the magnitudes of the negative values of the parameter $\mathrm{F}$ for the grooved plates without screens are such larger than those of the grooved plates with screens. 


\section{Drag Performance}

The percentage of $\Delta \mathrm{C}_{f} / \mathrm{C}_{\mathrm{fo}}$ for different flow conditions plotted in Figs 15 and 16 versus the Reynolds number for the smooth plates without grooves and $\mathrm{s}^{+}$for the grooved plates, respectively. In every case where, a screen was used, it was observed that the drag has a greater value than that of the case no screen. The drag increase is inversely proportional to screen size, which reflects the increase in turbulence promotion action when screen bars are closer to each other. The maximum percentage of increase in friction coefficient was about $10 \%$ in the case of smooth plate with free-stream turbulence intensity (Tu) of 3.2\% as shown in Fig. 15. In all cases where, a riblet plate was used without screens, the drag data showed that the drag reduction occurred with riblets whenever $\mathrm{s}^{+}<20-30$ for $\mathrm{h} / \mathrm{s}=1.3$ and 0.7 , respectively, which reflect the turbulence suppress action of grooved plates which results in a lower momentum transfer. The data shows that the drag reduction performance of the riblet is determined by $\mathrm{s}^{+}$and aspect ratio $(\mathrm{h} / \mathrm{s})$ as shown in Fig. 16. The maximum drag reduction was observed in the case of a grooved plate with $\mathrm{h} / \mathrm{s}=1.3$ to be $9 \%$. In cases where, a riblet plate was used with screens, the percentage of the maximum drag reduction reached $6.3 \%$ in the case of grooved plate with $\mathrm{h} / \mathrm{s}=1.3$ with $\mathrm{Tu}$ of $2.5 \%$ compared with the smooth surface without turbulence promoters. For grooved plate with $\mathrm{h} / \mathrm{s}=1.3$ without turbulence promoters at $\mathrm{s}^{+}=36.4$, the maximum percentage of increase in friction coefficient ${ }^{*}$ was about $10 \%$ of the smooth plate case. For $\mathrm{s}^{+}>20-30$, the friction coefficient increased considerably with maximum percentage of $15.7 \%$ at $\mathrm{s}^{+}=36.4$ of the smooth plate without promoters case, and that was observed in the case of grooved plate with $\mathrm{h} / \mathrm{s}$ $=1.3$ with $\mathrm{Tu}=3.2 \%$. The drag data of the micro-grooves plates are indicating that the zero-drag-reduction crossover point can extended by decreasing the aspect ratio (h/s) from 1.3 to 0.7 .

The $\Delta \mathrm{C}_{\mathrm{f}} / \mathrm{C}_{\mathrm{fo}}$ reduced from $5.5 \%$ and $8.5 \%$ increase for smooth plate with Tu of $2.5 \%$ and $3.2 \%$ to $6.3 \%$ and $4.5 \%$ reduction for grooved plate with Tu of $2.5 \%$ and $3.2 \%$, respectively, at $\mathrm{s}^{+}=13.7$ compared with the smooth surface without turbulence promoters. The skin coefficient increase over grooved plate with turbulence promoters compared with the grooved plate without turbulence promoters is less than the skin coefficient increase over smooth plate with turbulence promoters compared with the smooth plate without turbulence promoters. These results suggest increased the effectiveness of the riblets with turbulence promoters compared with the smooth surface with turbulence promoters as shown in Figs. 15 and 16. Also, figure 16 compares the present data for riblet drag to the data of Baron et al. [2] for aspect ratio $\mathrm{h} / \mathrm{s} 0.78$. Reasonable agreement between the present results and measured results of Baron et al. has been demonstrated. The discrepancy between the present results and results of Baron is typically within $10 \%$.

The comparison between the present experimental and the predicted results was carried out as shown in Figs. 15 and 16. The comparison shows that, the present numerical data may be considered consistent and it can give satisfactory results for the turbulent drag coefficient with an accuracy of $\pm 10 \%$ if compared with the experimental data. 


\section{CONCLUSIONS}

The effects of free-stream turbulence for smooth plate without grooves (riblets) on turbulent boundary layer drag reduction over plates with stream-wise micro-grooves. have been investigated experimentally and numerically. The main conclusions of the present study are as follows:

1. The bars, constituting the grid, act as a turbulence promoter which increase the possibility of vortices forming in the stream-wise and span-wise directions, which interact with the flow and result in a higher transport of momentum from the resisting wall to the fluid layers producing deceleration action near the wall.

2. The turbulence intensity is reduced by grooved surface for $\mathrm{s}^{+}<20-30 \mathrm{for} h / \mathrm{s}=1.3$ and 0.7 , respectively, compared with the smooth surface without screens (turbulence promoters). While the turbulence intensity is increased over the grooved surface with $\mathrm{s}^{+}>20-30$.

3. For smooth plate, the downward shift in log law of mean velocity is increased with increasing the free-stream turbulence or decreasing the grid size. The maximum downward shift was observed in the case of the turbulence intensity Tu of $3.2 \%$ to be about $6.7 \%$. The slope of the log law of the wall mean velocity profiles over the riblet surface with and without screens remains the same as that of the smooth surface without free-stream turbulence promoters; however, the intercept of the law is upward shift by riblets with $s^{+}<20-30$, and is the downward shift by riblets with $\mathrm{s}^{+}>20-30$.

4. The results indicate that parameter $F$ is negative when drag reduction occurs and positive when drag increase occurs. The positive values of the riblets function $F$ (downward shift) for the grooved plates with turbulence promoters are higher in magnitude in comparison to the grooved plates without turbulence promoters. While the magnitudes of the negative values of the $F$ for the grooved plates without screens are such larger than those of the grooved plates with screens.

5. The wall parameter $(E)$ in the logarithmic law of the wall was modified using experimental data to accommodate the parameter $F$ in terms of the free-stream turbulence, spacing $\left(\mathrm{s}^{+}\right)$in wall variables and riblet aspect ratio $(\mathrm{h} / \mathrm{s})$.

6. The drag reduction for the riblet surfaces was found to be dependent on the spacing of the riblets in law of the wall variables and riblet aspect ratio (h/s) regardless of the free-stream Reynolds number or upstream boundary layer
history.

7. The data show that the drag reduction occurred whenever $\mathrm{s}^{+}<20-30$ for $\mathrm{h} / \mathrm{s}=1.3$ and 0.7 , respectively. A maximum drag reduction of $9 \%$ occurred at approximately $\mathrm{s}^{+}=13.6$ for grooved plate without turbulence promoters. The percentage of the maximum drag reduction reached $6.3 \%$ in the case of grooved plate with $\mathrm{h} / \mathrm{s}=1.3$ with free-stream turbulence intensity of $\mathrm{Tu}=2.5 \%$ compared with the smooth surface without turbulence promoters. The drag data of the micro-grooves plates are indicating that the zero-drag-reduction crossover point can extended by

8. The maximum percentage of increase in friction coefficient was about $10 \%$ in the case of smooth plate with screens (turbulence promoters). For grooved plate with 
$\mathrm{h} / \mathrm{s}=1.3$ without turbulence promoters at $\mathrm{s}^{+}=36.4$, the maximum percentage of increase in friction coefficient was about $10 \%$ of the smooth plate case. For $\mathrm{s}^{+}>$ $20-30$, the friction coefficient increased considerably with maximum percentage of $15.7 \%$ at $\mathrm{s}^{+}=36.4$ of the smooth plate without turbulence promoters case, and that was observed in the case of grooved plate with $\mathrm{h} / \mathrm{s}=1.3$ with free-stream turbulence intensity of $\mathrm{Tu}=3.2 \%$. The results suggest increased the effectiveness of the riblets with turbulence promoters compared with the smooth surface with turbulence promoters.

9. The comparison between the present experimental and the predicted results shows that, the present numerical data may be considered consistent and it can give satisfactory results with an accuracy of $\pm 10 \%$ if compared with the experimental data.

\section{REFERENCES}

1. Afify, R., I. and Abd-Rabbo, M. F., "Turbulent Boundary Layer and Heat Transfer Characteristics Over Surfaces with Stream-Wise Riblets in Adverse Pressure Gradient," Proceedings of the Sixth International Conference on Energy and Environment, May, 11-14, 1998, Cairo, Egypt, pp. 285-311, (1998).

2. Baron, A., Quadrio, M., and Vigevano, L., "On the Boundary Layer/Riblets Interaction Mechanisms and the Prediction of Turbulent Drag Reduction" Int. J. Heat and Fluid Flow, Vol. 14, No. 4, pp. 324-332, (1993).

3. Walsh, M. J., Sellers, W. L., III, and McGinley, C. B., "Riblet Drag at Flight Conditions," Journal of Aircraft, Vol. 26, No. 6, pp. 570-575, (1989).

4. Gallagher, J. A., and Thomas, A. S. W., "Turbulent Boundary Layer Characteristics Over Streamwise Grooves," AIAA Paper No. 84-2185, AIAA 2nd Applied Aerodynamics Conference, Seattle, Washington, August 21-23, (1984).

5. Choi, K.-S., "Near-Wall Structure of a Turbulent Boundary Layer with Riblets," Journal of Fluid Mechanics, Vol. 208, pp. 417-458, (1989).

6. Choi, H., Moin, P., and Kim, J., "Direct Numerical Simulation of Turbulent Flow over Riblets," Journal of Fluid Mechanics, Vol. 255, pp. 503-539, (1993).

7. Lee, "Flow Field Analysis of Turbulent Boundary Layer Over a Riblet Surface," Experiments in Fluid, Vol. 30, pp. 153-166, (2001).

8. Anderson, G. W., Rohr, J. J., and Stanley, S. D., "The Combined Drag Effects of Riblets and Polymers in Pipe Flow," ASME Journal of Fluids Engineering, Vol. 115, pp. 213-221, (1993).

9. Wang, Z. Y. and Jovanovic, J., "Drag Characteristics of Extra-Thin-Fin-Riblets in an Air Flow Conduit," ASME Journal of Fluids Engineering, Vol. 115, pp. 222-226, (1993).

10.Viswanath, P. R. and Mukund, R., "Turbulent Drag Reduction Using Riblets on a Supercritical Airfoil at Transonic Speeds," AIAA Journal, Vol. 33, No. 5, pp. 945947, (1995).

11.Chu, D. C., and Karniadakis, G. E., "A Direct Numerical Simulation of Laminar and Turbulent Flow Over Riblet-Mounted Surfaces," Journal of Fluid Mechanics, Vol. 250, pp. 1-42, (1993). 
12.Goldstein, D., Handler, R., and Sirovich, L., "Direct Numerical Simulation of Turbulent Flow Over a Modelled Riblet Covered Surface," Journal of Fluid Mechanics, Vol. 302, pp. 333-376, (1995).

13.Sundaram, S., Viswanath, P. R., and Rudrakumar, S., "Viscous Drag Reduction Using Riblets on NACA 0012 Airfoil to Moderate Incidence," AIAA Journal, Vol. 34, No. 4, pp. 676-682, (1996).

14.Viswanath, P. R., and Mukund, R., "Turbulent Drag Reduction Using Riblets on a Supercritical Airfoil at Transonic Speeds," AIAA Journal, Vol. 33, No. 5, pp. 945947, (1995)

15.Vukoslavcevic, P., Wallace, J. M., and Balint, J.-L., "Viscous Drag Reduction Using Streamwise-Aligned Riblets," AIAA Journal, Vol. 30, No. 4, pp. 1119-1122, (1992).

16.Suzuki, Y., and Kasagi, N., "Turbulent Drag Reduction Mechanism Above a Riblet Surface," AIAA Journal, Vol. 32, No. 9, pp. 1781-1790, (1994).

17.Wang, J. J., "Experimental Study on the Turbulent Boundary Layer Flow over Riblets Surface," Fluid Dynamic-Research, Vol. 27, No. 4, pp. 217-229, (2000).

18.Grek, G. R., Kozlov, V. V., and Titarenko, S. V., "An Experimental Study of the Influence of Riblets on Transition," Journal of Fluid Mechanics, Vol. 315, pp. 31 49, (1996)

19.Bechert, D. W., Bruse, M., Hage, W., Hoeven, J. G. T. Van Der, and Hoppe, G., "Experiments on Drag-Reducing Surfaces and Their Optimization with an Adjustable Geometry," Journal of Fluid Mechanics, Vol. 338, pp. 59-87, (1997).

20.Dubief, Y., Djenidi L., and Antonia R. A., "The Measurement of $\partial u / \partial y$ in a Turbulent Boundary Layer Over a Riblet Surface," Int. J. Heat and Fluid Flow, Voil. 18, No. 2, pp. 183-187, (1997).

21.Simonich, J. C., and Bradshaw, P., "Effects of Free-Stream Turbulence on Heat Transfer Through A Turbulent Boundary Layer," J. Heat Transfer, Vol. 100, pp. $671,(1978)$.

22. Hancock, F. E. and Bradshaw, P., "The Effect of Free-Stream Turbulence on Turbulent Boundary Layers," J. Fluids Eng., Vol. 105, pp. 244, (1983).

23. Roach, P. E., and Brieley, D. H., "Influence of a Turbulent Free-Stream on Zero Pressure Gradient Transitional Boundary Layer Development; Part 1: Teat Case T3A and T3B," in "Numerical Simulation of Unsteady Flows and Transition to Turbulence" Cambridge University Press, USA, pp. 319-347, (1992).

24. Westin, K. J. A., Boiko, A.. V., and Muhammad-Klingmann, G. B., Kozlov, V. V., and Alfredsson, P. H., "Experiments in a Boundary Layer Subjected to FreeStream Turbulence; Part I: Boundary Layer Structure and Receptivity," Journal of Fluid Mechanics, Vol. 281, pp. 193-218, (1994).

25.Blair, M. F., "Influence of Free-Stream Turbulence on Turbulent Boundary Layer Heat Transfer and Mean Profile Development," J. Heat Transfer, Vol. 105, pp. 41, (1983).

26.MacMullin, R., Elord, W., and Rivir, R. B., "Effects of Free-Stream Turbulence from A Circular Wall Jet on a Flat Plate Heat Transfer and Boundary Layer Flow," ASME Paper 88-IGT-183, 3. Turbomachinary, Vol. 111, pp. 1, (1989).

27.Baskaran, V., Abdellatif, O. E., and Bradshaw, P., "Effects of Free-Stream Turbulence on Turbulent Boundary Layers with Convective Heat Transfer," Symposium on Turbulent Shear Flows, Stanford, (1989). 
28.Abdellatif, O. E., "The Effect of Free-Stream Turbulence on Turbulent Boundary Layer and Heat Transfer," Journal of Engineering Research, El Mattaria Faculty of Eng., Cairo, Egypt, Vol. 72, pp. 104-117, (2000).

29.Coles, D. E., and Hirst, E. A., "Proceeding Computation of Turbulent Boundary Layers," AFOSR-IFP-Stanford Conference, Vol. II, (1968).

30.Sheikholeslami, M. Z., "Computer-aided analysis of two-dimensional laminar and turbulent incompressible flows," Ph. D. Thesis, Dept. of Mechanical Engineering, Graduate College, The University of lows, lowa City, lowa, (1986).

31.Habib, M. A., Attya, A. E., and McEligot, D. M., "Calculation of Turbulent Flow and Heat Transfer in Channels With Streamwise-Periodic Flow," ASME Journal of Turbomachinery, Vol. 110, pp. 405-411, (1988).

32.Launder, B. E., and Spalding, D. B., Mathematical Models of Turbulence, Academic Press, London, New york, (1972).

33.Patanker, S. V., Numerical Heat Transfer and Fluid Flow, McGraw-Hill, New York, (1980).

34.Coles, D. E., "The Law of the Wake in Turbulent Boundary Layers," Journal of Fluid Mechanics, Vol. 1, pp. 191-226, (1956).

35.Hama, F. R., "Boundary Layer Characteristics for Smooth and Rough Surfaces," Trans. Soc. NAME, Vol. 62, pp. 333-354, (1954).

Dvorak, F. A., "Calculation of Compressible Turbulent Boundary Layers with Roughness and Heat Transfer," AIAA Journal, Vol. 10, pp. 1447-1451, (1972). 


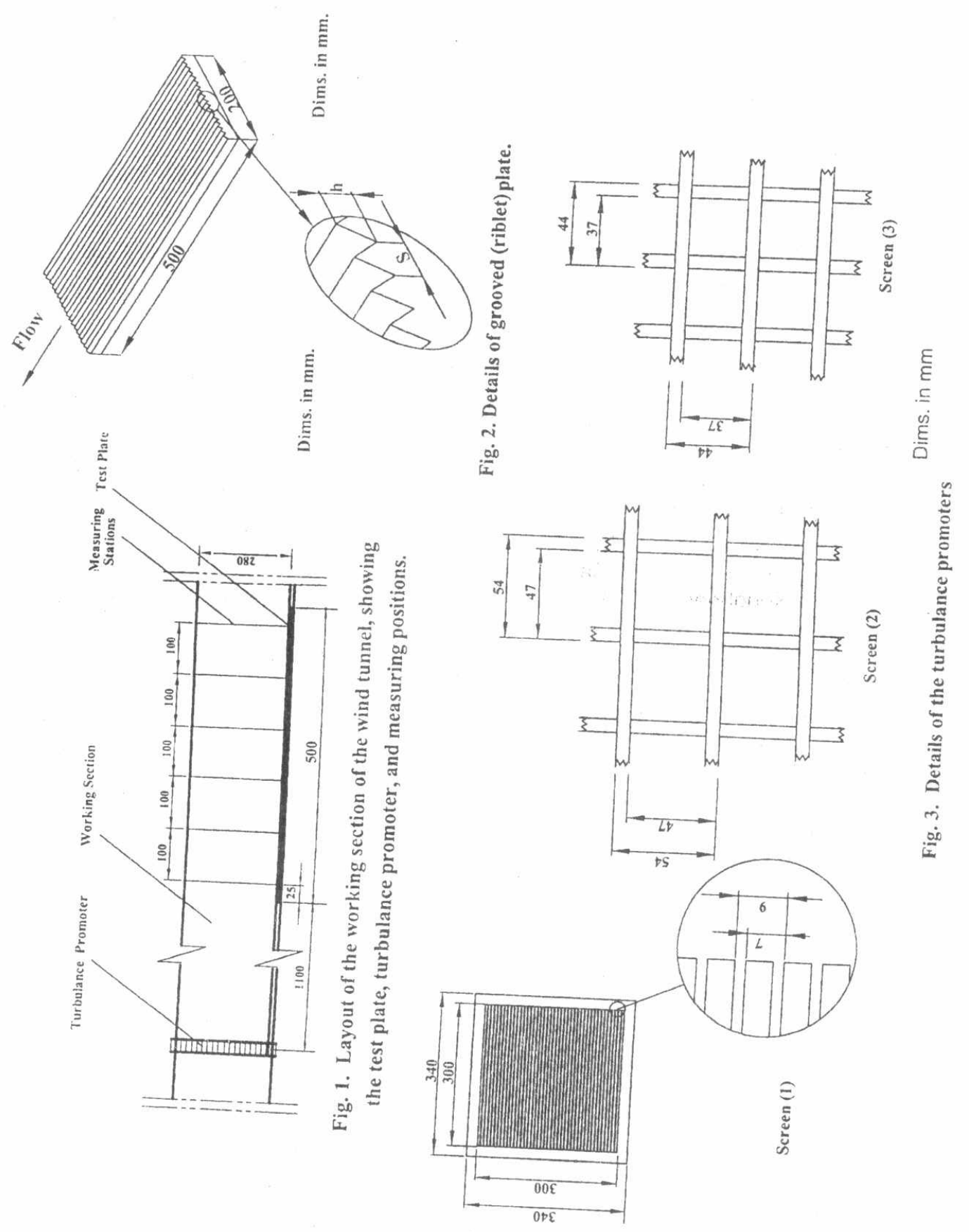



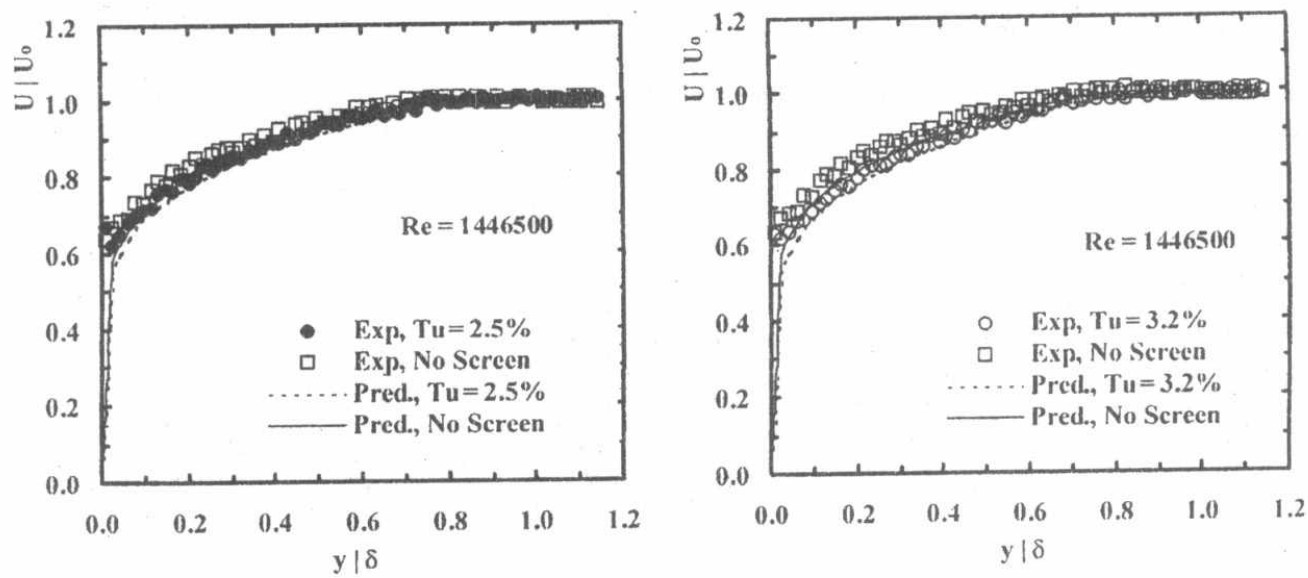

Fig. 4. Mean velocity profiles over smooth plate for different promoters.
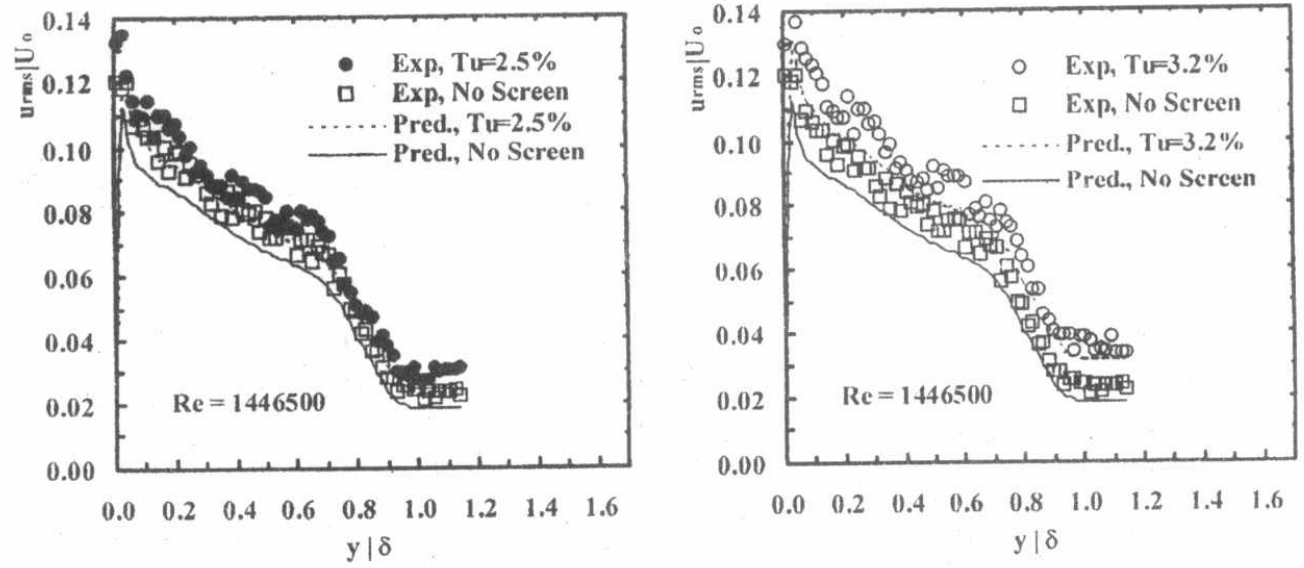

Fig. 5. Turbulence intensity profiles over smooth plate for different promoters.
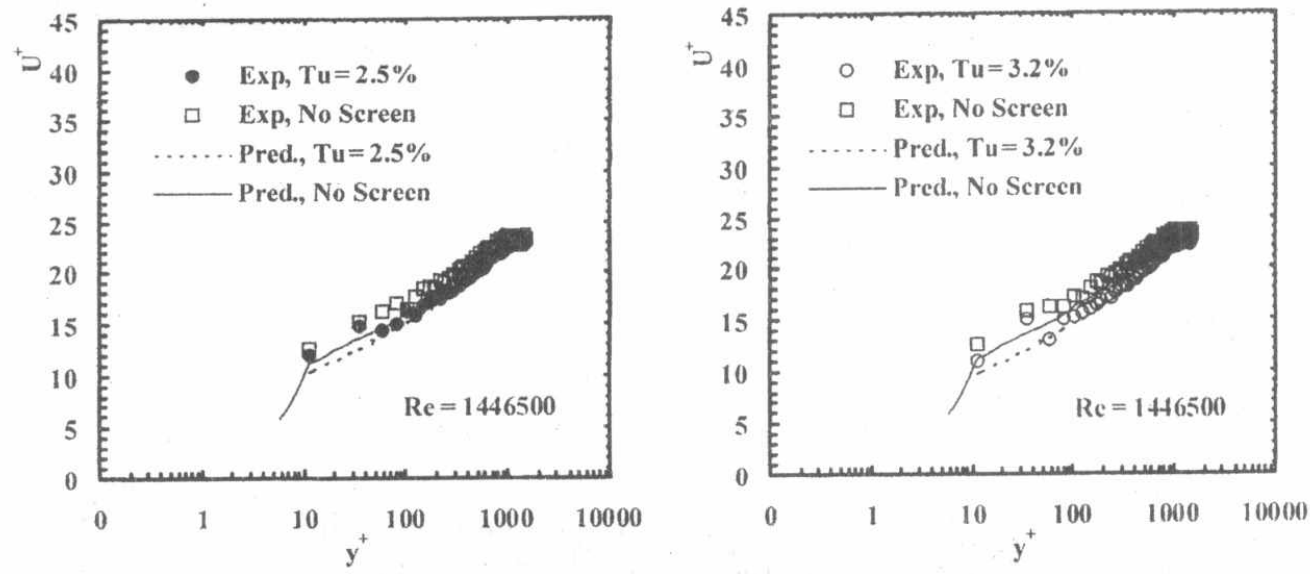

Fig. 6. Mean velocity profiles in wall coordinates over smooth plate for different promoters. 

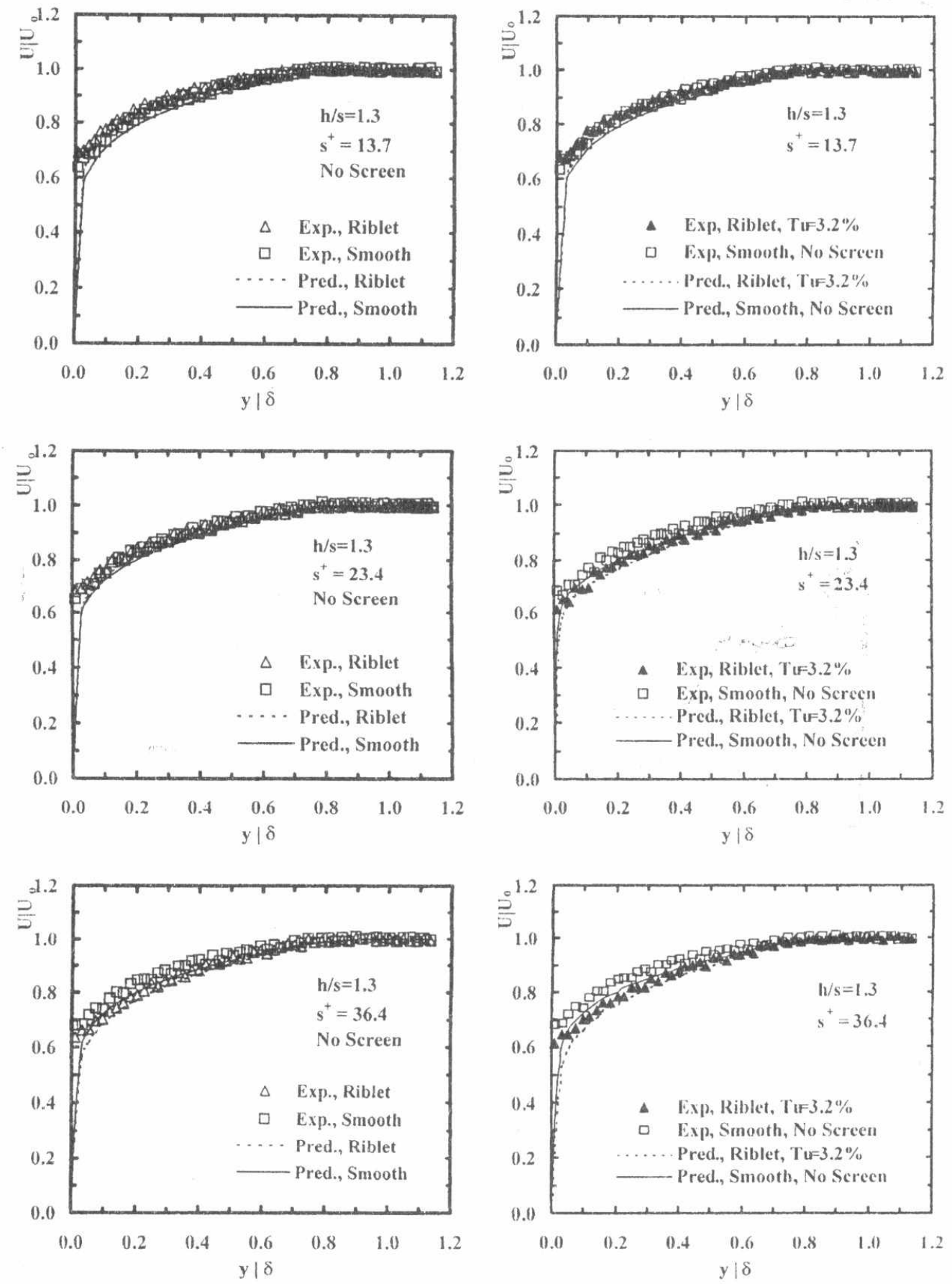

Fig. 7. Mean velocity profiles over grooved plate $(h / s=1.3)$ compared with smooth plate without turbulence promoters. 

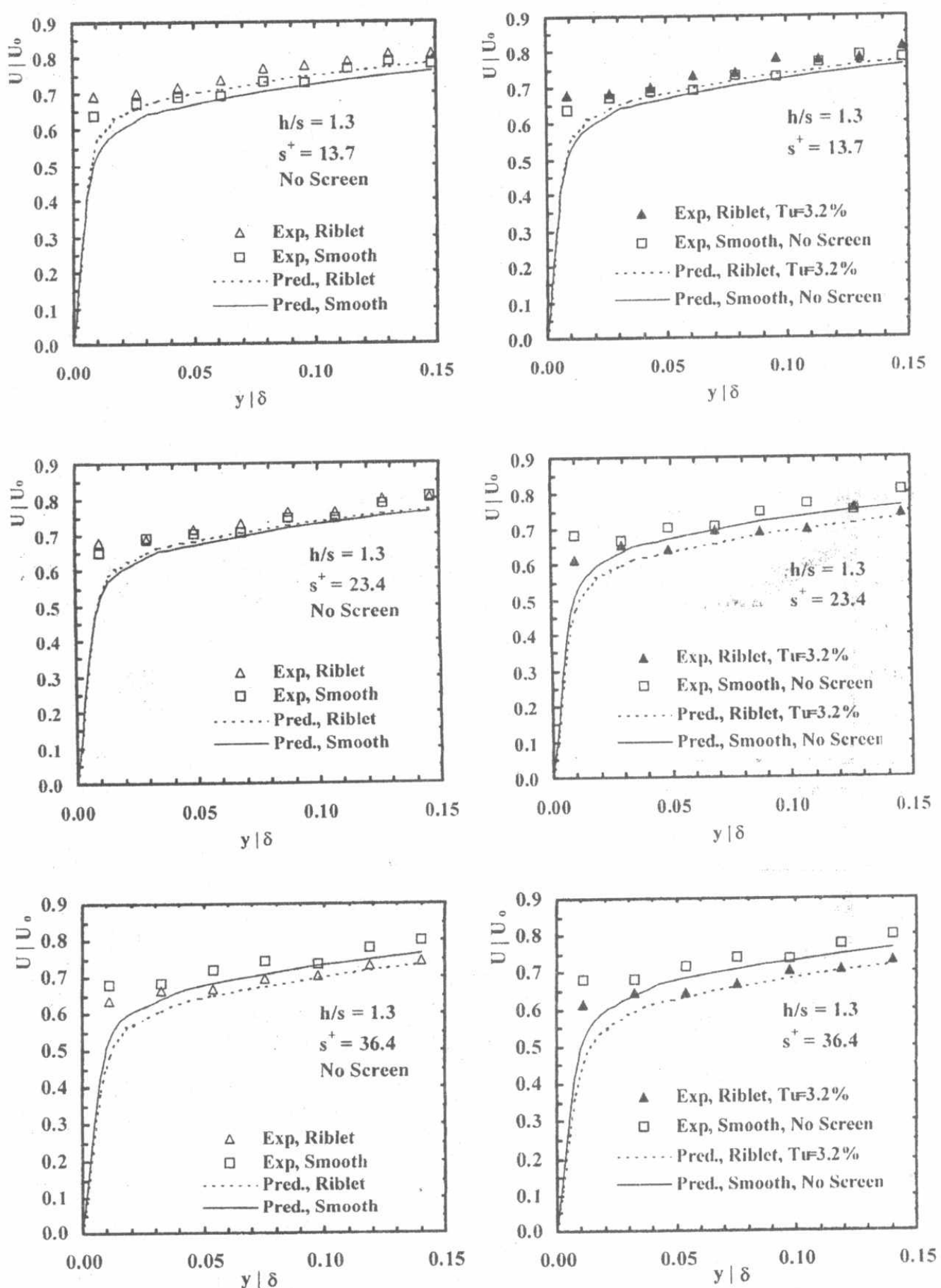

Fig. 8. Velocity profiles in the near wall region for riblet $(h / s=1.3)$. compared with smooth plate without turbulence promoters. 

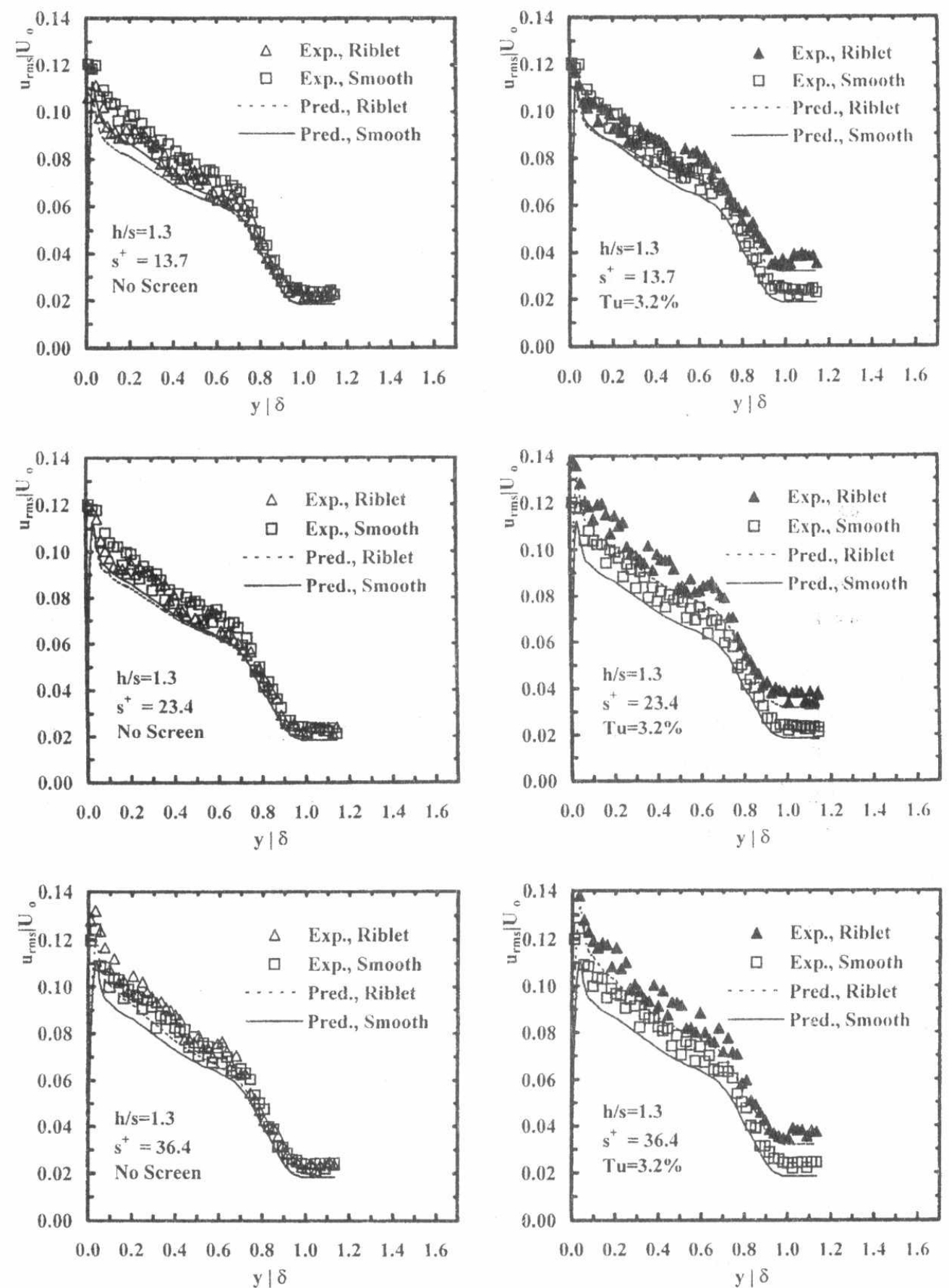

Fig. 9. Turbulence intensity profiles over grooved plate $(h / s=1.3)$ compared with smooth plate without turbulence promoters. 

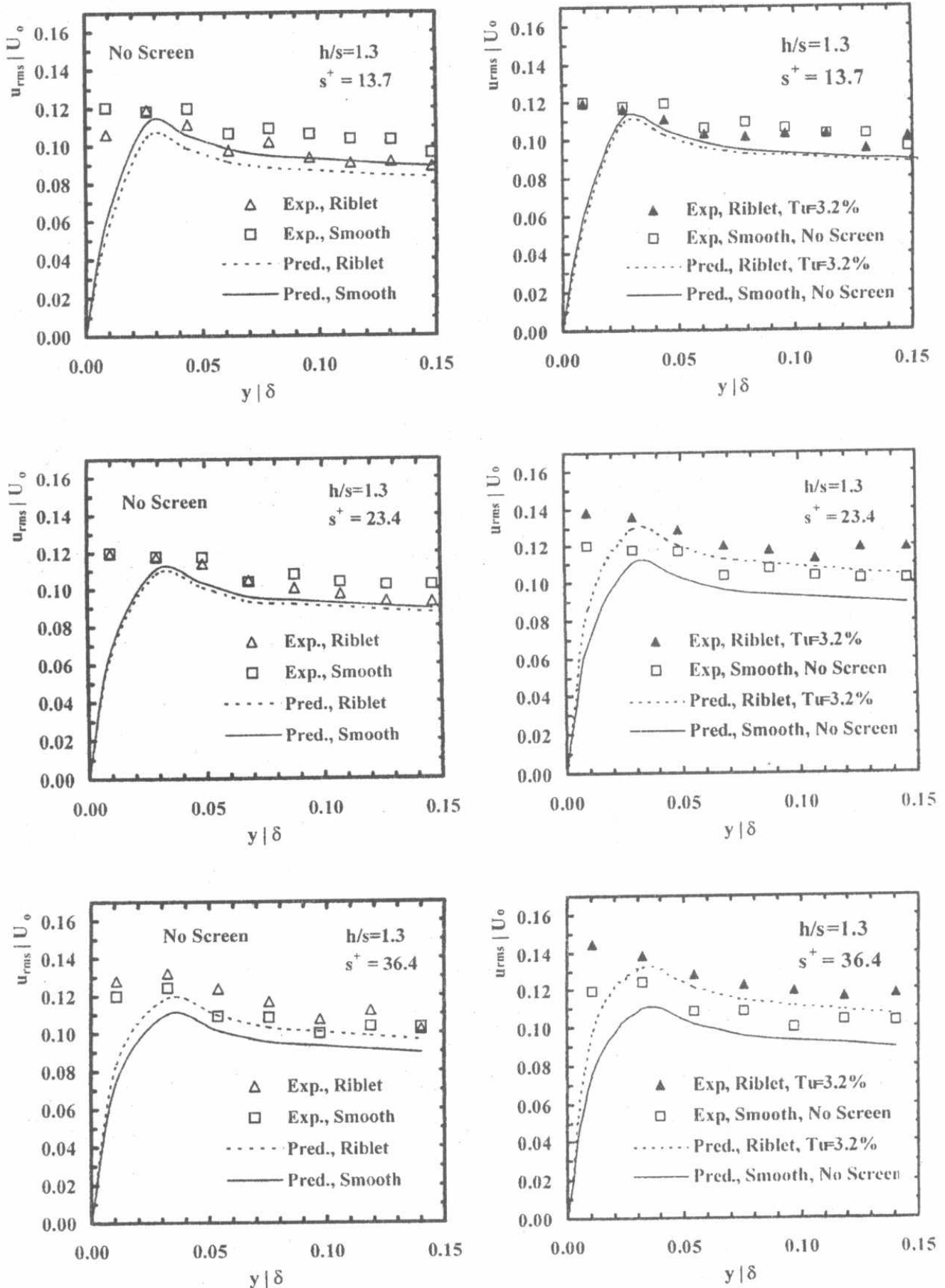

Fig. 10. Turbulence intensity profiles in the near wall region for riblet $(\mathrm{h} / \mathrm{s}=1.3)$ compared with smooth plate without turbulence promoters. 

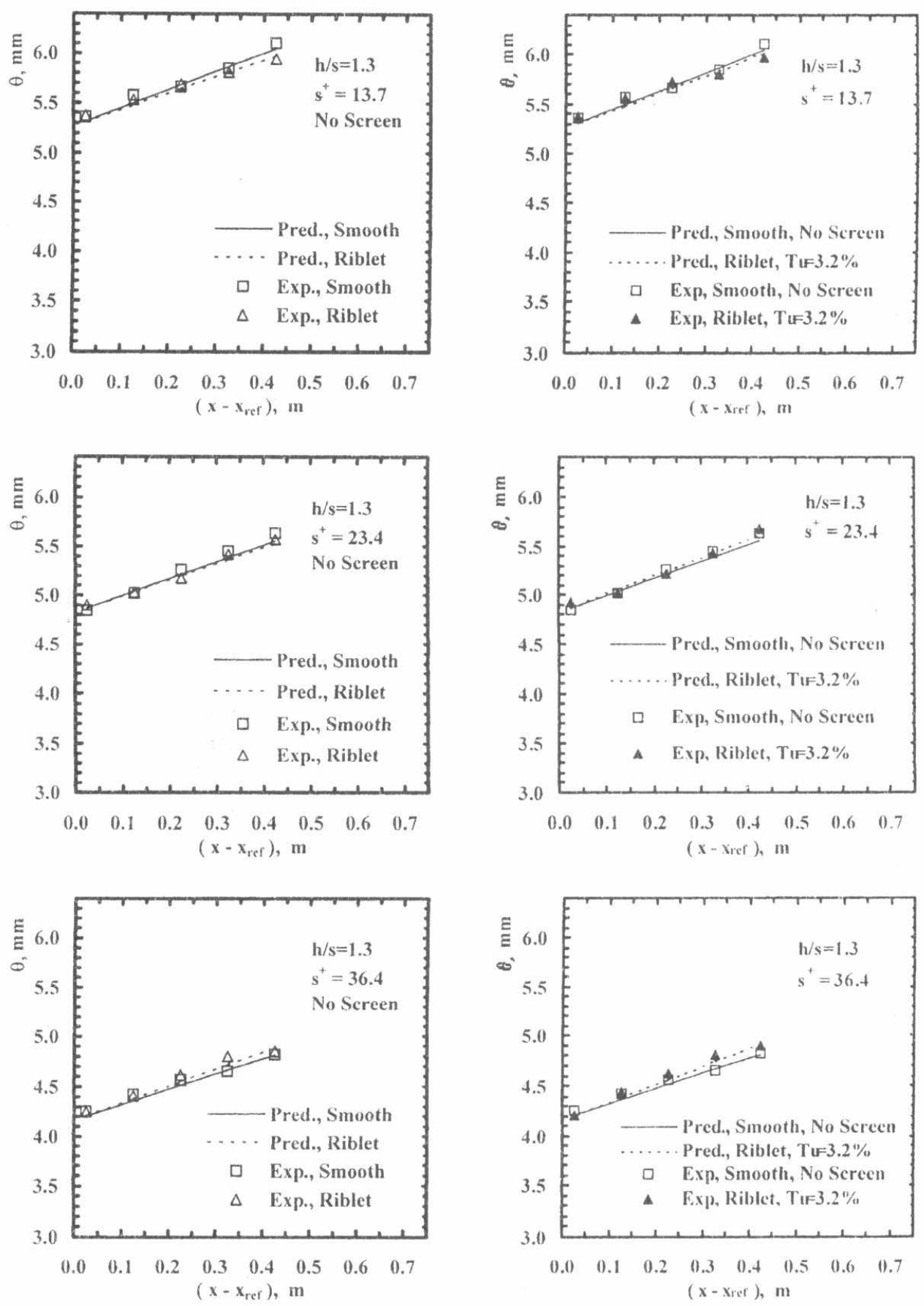

Fig. 11. Variation of boundary layer momentum thickness with streamwise distance $\left(x-x_{\text {ref }}\right)$ over grooved plate $(h / s=1.3)$ compared with smooth plate without turbulence promoters. 

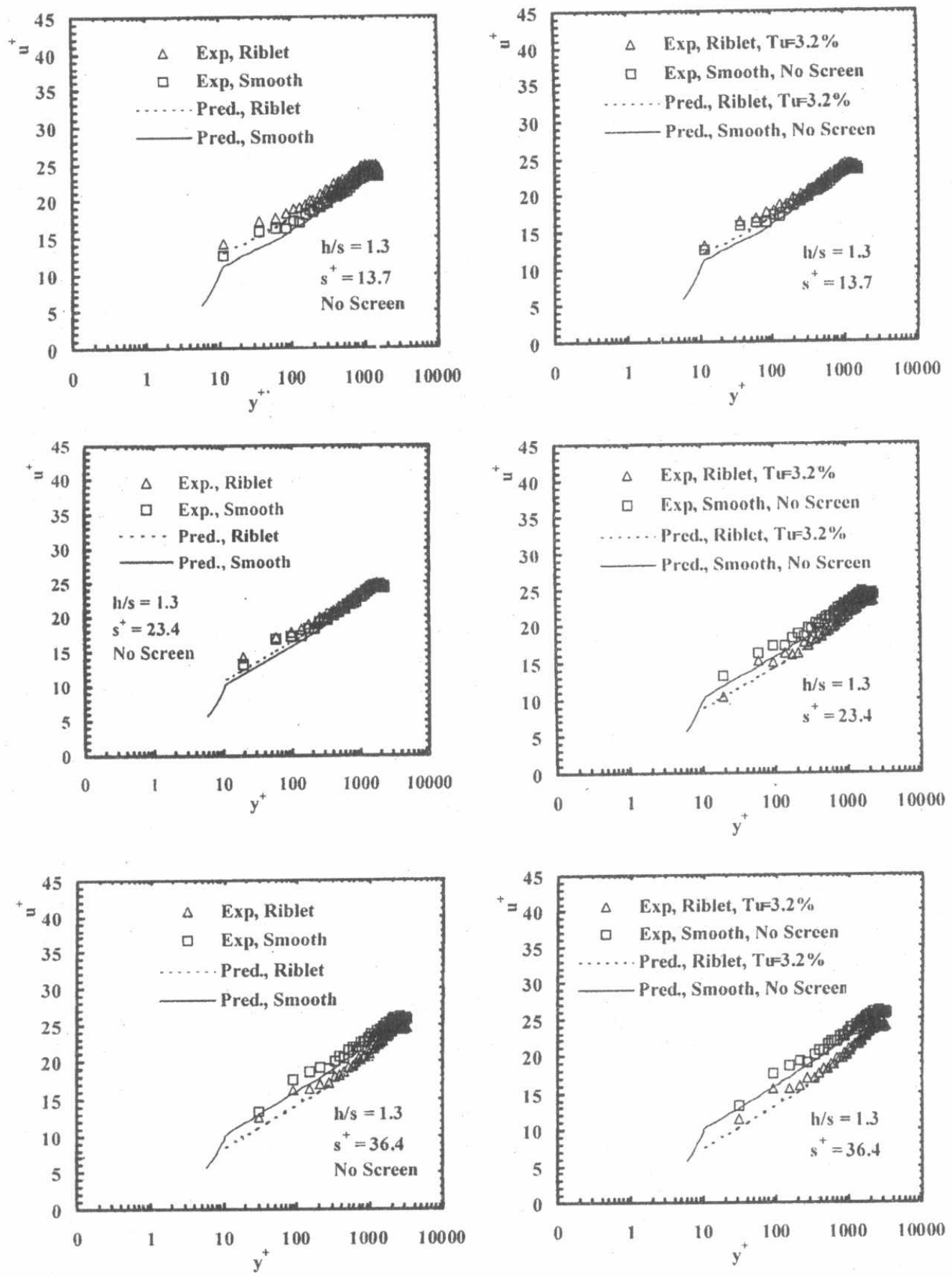

Fig. 12. Mean velocity profiles in wall coordinates over grooved plate $(h / s=1.3)$ compared with smooth plate without turbulence promoters. 